\title{
Unusual expression of Gaucher's disease: cardiovascular calcifications in three sibs homozygous for the $\mathrm{D} 409 \mathrm{H}$ mutation
}

Amparo Chabás, Bru Cormand, Daniel Grinberg, José M Burguera, Susana Balcells, José L Merino, Isabel Mate, José A Sobrino, Roser Gonzàlez-Duarte, Lluïsa Vilageliu

\begin{abstract}
Three sisters suffering from an unusual form of Gaucher's disease are described. These patients had cardiovascular abnormalities consisting of calcification of the ascending aorta and of the aortic and mitral valves. Neurological findings included ophthalmoplegia and saccadic eye movements in two patients, and tonicclonic seizures in the third. The three patients died, two of them after having undergone aortic valve replacement. Tissue was obtained from one of the sibs and fibroblast and liver $\beta$-glucocerebrosidase activity was reduced to $4 \%$ and $11 \%$ of mean normal values. Genotype analysis indicated that the patient was homozygous for the D409H mutation. It is tempting to relate the phenotype of severe cardiac involvement to the D409H/D409H genotype, although further cases will be needed before this association can be confirmed.
\end{abstract}

( $\mathcal{H}$ Med Genet 1995;32:740-742)

Gaucher's disease is characterised by glucocerebroside accumulation owing to deficiency of lysosomal $\beta$-glucocerebrosidase. Three types of the disease have been distinguished on the basis of the neurological involvement. Patients with type 1 are free of nervous system disease while neurological signs are present in patients with types 2 and 3 . The disorder mainly affects the liver, spleen, bone marrow, skeleton and, in types 2 and 3 , the brain. Cardiac complications are extremely rare in Gaucher's disease and mostly restricted to constrictive pericarditis in non-neuronopathic adult cases, or type $1 .{ }^{1}$

This autosomal recessive disease is caused almost exclusively by mutations in the gene encoding the lysosomal enzyme $\beta$-glucocerebrosidase (EC 3.2.1.45). The disease is particularly prevalent among the Ashkenazi Jewish population, in which only two mutations (N370S and $84 \mathrm{GG}$ ) account for 80 to $90 \%$ of the cases. In non-Jewish patients, the two most frequent mutations are N370S and L444P, accounting for 50 to $70 \% .^{2-4}$

In the Spanish Gaucher's disease population, a third frequent mutation is $\mathrm{D} 409 \mathrm{H} .{ }^{5}$ Here we report three sibs, homozygous for this mutation, suffering from an unusual form of Gaucher's disease. The three girls, the entire offspring of a healthy, non-consanguineous couple, were found to be affected with cardiovascular abnormalities consisting of calcification of the ascending aorta and of the aortic and mitral valves, in addition to ophthalmoplegia and the systemic findings characteristic of Gaucher's disease.

\section{Material and methods \\ PATIENTS}

Patients 1 and 2, the first and second girls born to a non-consanguineous couple, were admitted to hospital when 17 and 16 years old. Patient 1 was patient III. 2 in Cormand et al. ${ }^{5}$ The first symptoms were recurrent epistaxis and dyspnoea on exercise. Both had splenomegaly and, in patient 1, hepatomegaly was also present. Neurological manifestations started at 16 and 15 years of age and consisted of left ophthalmoplegia, saccadic eye movements, and hyporeflexia. Strabismus in the left eye and corneal opacities were also noted. Both patients had pes cavus. Laboratory tests showed pancytopenia, increased serum acid phosphatase activity, and normal serum calcium and phosphate. A bone marrow aspirate was consistent with the diagnosis of Gaucher's disease. Echocardiography and fluoroscopy disclosed substantial calcification of the mitral and aortic valves and of the ascending aorta. Doppler examination and cardiac catheterisation showed severe aortic stenosis with mild aortic regurgitation and moderate mitral stenosis. The patients died when 19 and 17 years old, one of them after receiving corrective surgery for aortic valve replacement. Necropsy was denied. Patient 3 was the youngest of the three sisters but the first to develop the disease. Hepatosplenomegaly was detected at 18 months of age. She underwent splenectomy at the age of 6 years to correct severe pancytopenia and examination of tissue disclosed the characteristic Gaucher cells. At 10 years of age she presented with generalised tonic-clonic seizures. Cardiovascular involvement was similar to her sisters. The patient died at 13 years during the postoperative course after surgical correction.

BIOLOGICAL MATERIAL

Skin fibroblast cultures were established according to routine procedures in Eagle's minimum essential medium. Aqueous homogenate of liver was centrifuged at $100000 \mathrm{~g}$, and the pellet was resuspended in water and used as 
Residual $\beta$-glucocerebrosidase activity in tissues of patient 1, in types 1 and 3 Gaucher's disease patients, and controls

\begin{tabular}{|c|c|c|c|c|c|}
\hline & \multicolumn{2}{|c|}{$\begin{array}{l}\text { Stearoyl- } \beta \text {-glucocerebrosidase } \\
\text { (nmol/h/mg protein) }\end{array}$} & \multicolumn{3}{|c|}{$\begin{array}{l}\text { MU- } \beta \text {-glucosidase } \\
\text { (nmol/h/mg protein) fibroblasts }\end{array}$} \\
\hline & Liver* & Fibroblasts* & $T+T X$ & $P S+S A P$ & $\begin{array}{l}P S+S A P \text { ratio } \\
T+T X\end{array}$ \\
\hline \multicolumn{6}{|l|}{ Control } \\
\hline Mean (SD) & $\begin{array}{l}15 \cdot 0(7 \cdot 6) \\
(n=5)\end{array}$ & $\begin{array}{l}177(46) \\
(\mathrm{n}=20)\end{array}$ & $\begin{array}{l}198(80) \\
(n=55)\end{array}$ & $\begin{array}{l}343(122) \\
(\mathrm{n}=30)\end{array}$ & $1 \cdot 3(0 \cdot 2)$ \\
\hline Patient 1 & $2 \cdot 1$ & 19 & $7 \cdot 6$ & $9 \cdot 5$ & $1 \cdot 2$ \\
\hline \multicolumn{6}{|l|}{ Type 1} \\
\hline Mean (SD) & & $\begin{array}{l}20 \cdot 1(5 \cdot 8) \\
(n=7)\end{array}$ & $\begin{array}{l}18 \cdot 2(9 \cdot 6) \\
(n=18)\end{array}$ & $\begin{array}{l}77(41) \\
(n=18)\end{array}$ & $4 \cdot 2(1 \cdot 6)$ \\
\hline \multicolumn{6}{|l|}{ Type 3} \\
\hline $\begin{array}{l}\text { No } 1 \\
\text { No } 2\end{array}$ & ND & & $\begin{array}{l}4 \cdot 5 \\
2 \cdot 2\end{array}$ & $\begin{array}{l}7 \cdot 1 \\
4 \cdot 4\end{array}$ & $\begin{array}{l}1 \cdot 6 \\
2 \cdot 0\end{array}$ \\
\hline
\end{tabular}

* Assayed in the presence of taurocholate (T) and Triton X-100 (TX).

† Assayed in the presence of T and TX, or with phosphatidylserine (PS) and a sphingolipid activator protein preparation (SAP).

$\mathrm{ND}=$ not detectable.

amplified by Wizard ${ }^{\mathrm{TM}}$ PCR Preps (Promega) and sequenced using the Sequenase Version 2.0 DNA Sequencing Kit (USB) according to the manufacturer's conditions.

\section{Results}

Enzymatic and mutation genotype analysis were carried out in patient 1 .

\section{ENZYMATIC ANALYSIS}

In the patient's cultured fibroblasts $\beta$-glucocerebrosidase was reduced to $4 \%$ (substrate MU- $\beta$ Glc) and to $11 \%$ (substrate stearoylglucocerebroside) of normal levels. With the natural substrate, liver enzyme activity was $14 \%$ of mean controls. Measurement of residual enzyme activity was also carried out in the presence of the natural activators, since a selective reconstitution of glucocerebrosidase activity in type 1 patients, but not in types 2 or 3, by $\mathrm{PS}^{8}$ and $\mathrm{SAP}^{9}$ has been pointed out. In the presence of SAP and PS, $\beta$-glucosidase displayed low levels of activity $(9.5 \mathrm{nmol} / \mathrm{h} / \mathrm{mg}$ protein) so that the mutant enzyme expressed $3 \%$ of control mean activity. This value as well as the ratio $\mathrm{PS}+\mathrm{SAP} / \mathrm{T}+\mathrm{TX}$ is similar to those found in two cases with type 3 Gaucher's disease (table). dium taurocholate $(\mathrm{T}, 1.5 \% \mathrm{w} / \mathrm{v})$ and Triton $\mathrm{X}-100$ (TX, $0 \cdot 2 \% \mathrm{v} / \mathrm{v}$ ). $\beta$-glucocerebrosidase activity in patient's fibroblasts was also measured in the presence of the physiological activators phosphatidylserine (PS, $5 \mu \mathrm{g}$ ) and an activator protein preparation (SAP, $150 \mu \mathrm{g}$ ) using MU- $\beta$ Glc as substrate.

\section{DETECTION OF THE D409H MUTATION}

Genomic DNA amplification and allele specific oligonucleotide (ASO) hybridisation were carried out as previously described. ${ }^{5}$ For SSCP analysis, a different fragment of $174 \mathrm{bp}$, corresponding to the $3^{\prime}$ end of exon 9, was amplified using the following primers: $5^{\prime}$ ACTGGAACCTTGCCCTGAAC-3' and 5'ATAGGCCTGGTATGGAATGG-3'. SSCP conditions were those described in Bayés et al. ${ }^{7}$ For direct sequencing, PCR products were

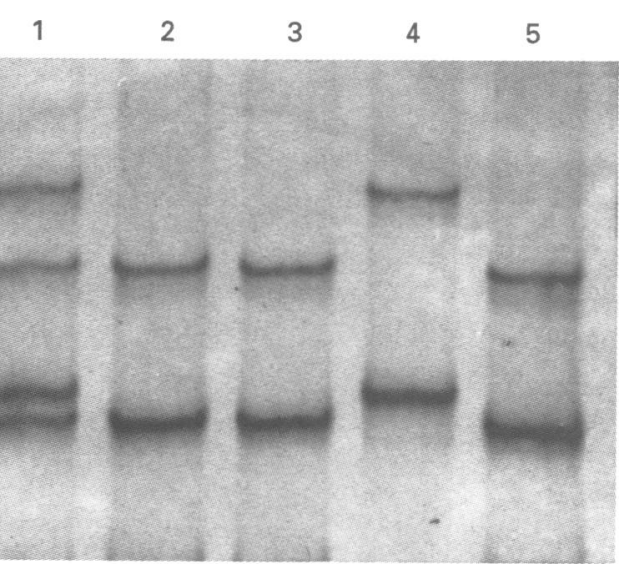

Figure 1 SSCP analysis of part of exon 9 of the $\beta$ glucocerebrosidase gene. Lane 5 corresponds to a healthy subject. The sample from patient 1 (homozygous for the D409H mutation) is shown in lane 4 . The patient in lane 1 is heterozygous for $D 409 H$, while the two other patients (lanes 2 and 3) do not bear mutations in this region of the gene.

\section{MUTATION ANALYSIS}

Mutation analysis on the DNA of patient 1 was carried out by SSCP analysis and ASO hybridisation (not shown), and confirmed by sequencing. Fig 1 shows the SSCP analysis carried out on amplified DNA from exon 9 of patient 1 (lane 4), of a healthy subject (lane 5), and of three other unrelated Gaucher's disease patients, one of them heterozygous for the 409 mutation (lane 1). The three different patterns, corresponding to homozygous for, heterozygous for, and non-carrier of the 409 mutation, are clearly distinguished.

The rest of the glucocerebrosidase gene was exhaustively analysed to rule out the presence of other mutations. Genomic DNA was amplified by PCR in 14 overlapping fragments which covered all the coding region of the gene. Four different SSCP conditions were tested for each fragment. No additional abnormal SSCP patterns were detected.

Sequencing of amplified exon 9 DNA shows the $\mathrm{G}$ to $\mathrm{C}$ transversion leading to the $\mathrm{D} 409 \mathrm{H}$ substitution (fig 2).

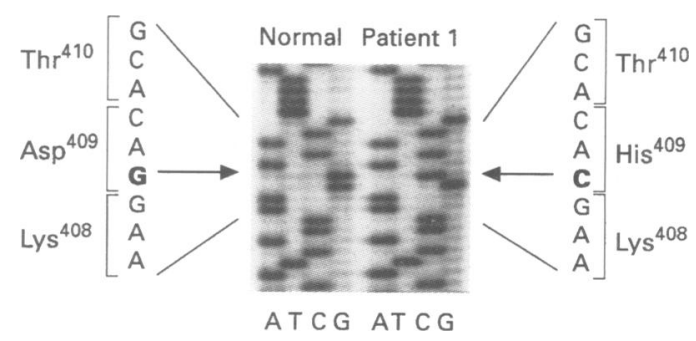

Figure 2 Sequence analysis of exon 9 of the $\beta$ glucocerebrosidase gene. PCR products from patient 1 and a normal subject were directly sequenced as described in Material and methods. Patient 1 is homozygous for a $G$ to $C$ transversion (arrow) at cDNA position 1342, resulting in an $A s p^{409}$ to His substitution. 


\section{Discussion}

Cardiac involvement consisting of constrictive pericarditis ${ }^{10-12}$ and diffuse infiltration of the myocardium by Gaucher cells ${ }^{13}$ has been described in patients with type 1 Gaucher's disease. In these patients constriction and calcification of the pericardium were related to unrecognised haemorrhagic pericarditis. ${ }^{12}$

Heart disease has been considered a frequent finding in patients with type $3 \mathrm{~b}$ Gaucher's disease. ${ }^{14}$ However, complications of the cardiovascular system of a similar extent and severity to those present in our three patients have only been reported in a 15 year old boy with Gaucher's disease and cardiac abnormalities also consisting of calcification of the ascending aorta and aortic and mitral valves. ${ }^{15}$ No neurological evaluation of this child was provided. Recently, two sibs with Gaucher's disease and mitral and aortic valve lesions have been reported. ${ }^{16}$

In our patients, the neurological manifestations were restricted to ophthalmoplegia and dysmetric saccadic eye movements (patients 1 and 2) and to myoclonic seizures (patient 3). Reconstitution of mutant glucocerebrosidase activity by PS and SAP confirmed the assignment of these patients to the subacute neuronopathic form of Gaucher's disease. The importance of oculomotor disturbances in the diagnosis of certain forms of type 3 has been pointed out by Stowens et al, ${ }^{17}$ being in some patients the sole manifestation of the disease. ${ }^{18}$ Interestingly, gaze paralysis was also reported in a type 3 Gaucher's disease case presenting with aortic involvement. ${ }^{19}$

Genotyping showed that patient 1 is homozygous for mutation $\mathrm{D} 409 \mathrm{H}$. This is the third most frequent mutation detected in Spanish Gaucher's disease patients, although it only accounts for $5 \cdot 7 \%$ of mutated alleles. ${ }^{5}$

A single allele $\mathrm{D} 409 \mathrm{H}$ does not predict development of neurological disease including ophthalmoplegia. In fact, from a series of 46 Spanish patients with the disease, this allele was present in the heterozygous state in one out of 36 patients with type $1(1.38 \%)$, in one out of seven children with type $2(7 \cdot 14 \%)$, and in one out of three unrelated cases with type 3 Gaucher's disease (apart from patient 1 and her sisters, homozygous for the mutation). Nevertheless, none of the patients carrying a single copy of the $\mathrm{D} 409 \mathrm{H}$ allele was suffering from either heart disease or ophthalmoplegia.

It is tempting to relate homozygosity for mutation $\mathrm{D} 409 \mathrm{H}$ to severe cardiac involvement in Gaucher's disease although further cases are needed before this association can be claimed. In this respect, a group of Arab patients homozygous for the $\mathrm{D} 409 \mathrm{H}$ mutation presenting heart disease with similar symptoms to those of our patients has been reported. ${ }^{20}$

Should this association be proven, it would provide the first clear genotype-phenotype correlation in neuronopathic Gaucher's disease.

The authors thank R Rycroft for revising the English version of the manuscript. Bru Cormand is a recipient of a fellowship from the CIRIT (Generalitat de Catalunya). This work was partially supported by CICYT (SAF93-0479-C02-01).

1 Barranger JA, Ginns EI. Glucosylceramide lipidoses: Gaucher disease. In: Scriver CR, Beaudet AL, Sly WS, Valle D, eds. The metabolic basis of inherited disease. New York: McGraw-Hill, 1989:1677-97

2 Beutler E. Gaucher disease: new molecular approaches to diagnosis and treatment. Science 1992;256:794-9.

3 Sibille A, Eng CM, Kim SJ, Pastores G, Grabowski GA. Phenotype/genotype correlations in Gaucher disease type I-clinical and therapeutic implications. Am 7 Hum Genet 1993;52:1094-101.

4 Horowitz M, Zimran A. Mutations causing Gaucher disease. Hum Mutat 1994;3:1-11.

5 Cormand B, Vilageliu L, Burguera JM, et al. Gaucher's disease in Spanish patients: analysis of eight mutations. Hum Mutat 1995;5:303-9.

6 Chabás A, Guardiola A, Burguera JM. An activator protein of oligosaccharide sialidase. Biochem Int 1987;15:449-57.

7 Bayés M, Valverde D, Balcells S, et al. Evidence against involvement of recoverin in autosomal recessive retinitis involvement of recoverin in autosomal recessive retinitis

pigmentosa in 42 Spanish families. Hum Genet (in press).
8 Glew RH, Daniels LB, Clark LS, Hoyer SW. Enzymic differentiation of neurologic and nonneurologic forms of Gaucher's disease. $\mathcal{F}$ Neuropathol Exp Neurol 1982;41: 630-41.

9 Wenger DA, Roth S. Homozygote and heterozygote identification. In: Desnick RJ, Gatt S, Grabowski GA, eds. Gaucher disease: a century of delineation and research. New York: Alan R Liss, 1982:551-72.

10 Zlotnick A, Groen JJ. Observations on a patient with Gaucher's disease. Am $\mathcal{f}$ Med 1961;30:637-40.

11 Harvey PKP, Jones MC, Anderson EC. Pericardial abnormalities in Gaucher's disease. Br Heart 7 1969:31: 603-6.

12 Tamari I, Motro M, Neufeld HN. Unusual pericardial calcification in Gaucher's disease. Arch Intern Med 1983; 143:2010-11.

13 Smith RRI, Hutchins GMH, Sack GH, Ridolfi RL. Unusual cardiac, renal and pulmonary involvement in Gaucher's cardiac, renal and pulmonary involve
disease. $A m \mathcal{F} M e d$ 1978;65:352-60.

14 Patterson MC, Horowitz M, Abel RB, et al. Isolated horizontal supranuclear gaze palsy as a marker of severe systemic involvement in Gaucher's disease. Neurology 1993;43:1993-7.

15 Casta A, Hayden K, Wolf WJ. Calcification of the ascending aorta and aortic and mitral valves in Gaucher's disease. Am $\mathcal{F}$ Cardiol 1984;54:1390-1.

16 Saraçlar M, Atalay S, Koçak N, Ozkutlu S. Gaucher's disease with mitral and aortic involvement: echocardiographic findings. Pediatr Cardiol 1992;13:56-8.

17 Stowens DW, Chu FC, Cogan DG, Barranger JA. Oculomotor deficits in Gaucher disease. In: Desnick RI, ulomotor defcits is Gatt S, Grabowski G, eds. Gaucher disease: a century of delineation.

18 Gross-Tsur V, Har-Even Y, Gutman I, Amir N. Oculomotor apraxia: the presenting sign of Gaucher disease. Pediatr apraxia: the presenting

19 Wilson ER, Barton NW, Barranger JA. Vascular involvement in type 3 neuronopathic Gaucher's disease. Arch Pathol Lab Med 1985;109:82-4

20 Horowitz M, Zimran A. Genotype-phenotype correlation in Gaucher disease. In: Humphries SE, Malcolm S, eds. From genotype to phenotype. Oxford: BIOS Scientific Publishers, 1994:67-81. 